\title{
Growth Control of ZnO Nano-Crystals by Multi-Beam Interference Patterning
}

\author{
Daisuke NAKAMURA, Tetsuya SIMOGAKI, Kota OKAZAKI, Mitsuhiro HIGASHIHATA, and Tatsuo OKADA \\ Graduate School of Information Science and Electrical Engineering, Kyushu University, \\ 744 Motooka, Nishi-ku, Fukuoka 819-0395, Japan \\ E-mail: dnakamura@ees.kyushu-u.ac.jp
}

\begin{abstract}
We have succeeded in controlling growth density of the $\mathrm{ZnO}$ nanowires by introduction of a $\mathrm{ZnO}$ buffer layer. Low-density hexagonal cone-shape $\mathrm{ZnO}$ cores are formed on the buffer layer, and vertically-aligned $\mathrm{ZnO}$ nanowires are grown on the cores. The density of the nanowires was decreased by laser irradiation to the buffer layer before growth of the $\mathrm{ZnO}$ nanowires. In addition, periodic growth of $\mathrm{ZnO}$ nano-crystals was demonstrated using four beam interference patterning.

DOI: $10.2961 / \mathrm{jlmn} .2013 .03 .0004$
\end{abstract}

Keywords: $\mathrm{ZnO}$, nano-crystal, pulsed-laser deposition, interference laser irradiation

\section{Introduction}

One-dimensional (1D) nanomaterials have received increasing attention due to their unique properties. Among these materials, zinc oxide $(\mathrm{ZnO})$ nano-crystal is great interest for optoelectronic applications in particular ultraviolet (UV) region such as UV-LEDs [1,2], UV-lasers [3], and UV-photosensors [4], due to the unique electronic and optoelectronic properties, which is wide band gap $(3.37 \mathrm{eV})$ and large exciton binding energy $(60 \mathrm{meV})$.

For the practical optoelectronic applications based on the $\mathrm{ZnO}$ nano-crystals, however, fabrication of layered structures for $p$ - $n$ junction and control of nanowire growth direction, shape, density, and position are essentially required. As regards control of shape, in our study, we have succeeded in growing various $\mathrm{ZnO}$ nano-crystrals, such as nanowires, nanowalls, and nanorods, by nanoparticleassisted pulsed laser deposition (NAPLD) with changing growth conditions. Concerning the growth direction of the $\mathrm{ZnO}$ nano-crystals, vertically- and horizontally-aligned $\mathrm{ZnO}$ nanowires have been achieved by using a preannealed sapphire substrate [5,6]. A control of the density have been achieved by varying the repetition rate and laser fluence of the ablation laser [7]. In addition, we found that preparation of a $\mathrm{ZnO}$ buffer layer before growth of the nanowires affects the density and the alignment of the nanowires. However, control of position has not yet been realized in NAPLD. In order to make patterned-structures, a lithographic or imprinting technique is generally used [810]. Unfortunately, however, they need complex procedures and a catalyst. In this study, a simple method of laser irradiation to the buffer layer was introduced to control the growth position of $\mathrm{ZnO}$ nano-crystals. The density of the nanowire grown on laser-irradiated buffer layer clearly decreased. Thus, more active control of not only the density but the growth position is expected by introduction of the laser irradiation to buffer layer without complex procedures and catalysts. In the experiment, interference laser irradiation was adopted for patterned growth of the $\mathrm{ZnO}$ nano-crystals.

\section{Experiment}

In this experiment, a sintered source target of $\mathrm{ZnO}$ was used in synthesizing $\mathrm{ZnO}$ nano-crystals. An $a$-plane sapphire substrate $(10 \mathrm{~mm} \times 10 \mathrm{~mm} \times 0.5 \mathrm{~mm})$ was put on a $\mathrm{SiC}$ heater in a vacuum chamber and the target-substrate distance was set to be $40 \mathrm{~mm}$. The $\mathrm{ZnO}$ target was ablated with the third harmonics of a Q-switched Nd:YAG laser at $355 \mathrm{~nm}$ with a repetition rate of $10 \mathrm{~Hz}$ and a fluence of about $1 \mathrm{~J} / \mathrm{cm}^{2}$. The irradiated spot size was about $2 \mathrm{~mm}$ in a diameter. A ZnO buffer layer was deposited on the sapphire substrate at a background oxygen pressure of $3.3 \mathrm{~Pa}$ with a substrate temperature of $650{ }^{\circ} \mathrm{C}$ for 2 minutes. The thickness of the buffer layer was about $100 \mathrm{~nm}$. After deposition the buffer layer, the sample was taken out from the chamber and irradiated by a single Nd:YAG laser pulse of 355 $\mathrm{nm}$. Subsequently, the irradiated sample was placed in the chamber again, and then $\mathrm{ZnO}$ nano-crystals were grown on the buffer layer at background argon gas of $27 \mathrm{kPa}$ and a laser fluence of $0.5 \mathrm{~J} / \mathrm{cm}^{2}$ with a substrate temperature of $750{ }^{\circ} \mathrm{C}$ for 20 minutes (12000 pulses).

\section{Results and discussions}

\subsection{Laser irradiation to $\mathrm{ZnO}$ buffer layer}

Fig. 1 shows the atomic force microscopy (AEM) images of $\mathrm{ZnO}$ buffer layers of as-grown and the laser-
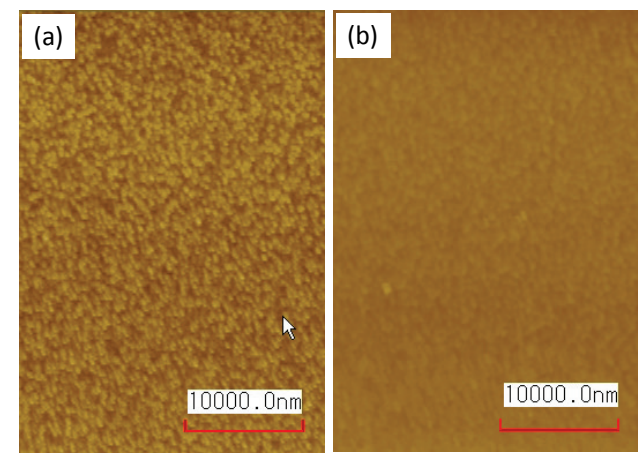

Fig. 1 AFM images of $\mathrm{ZnO}$ buffer layer, (a)asgrown surface and (b) laser-irradiated surface. 


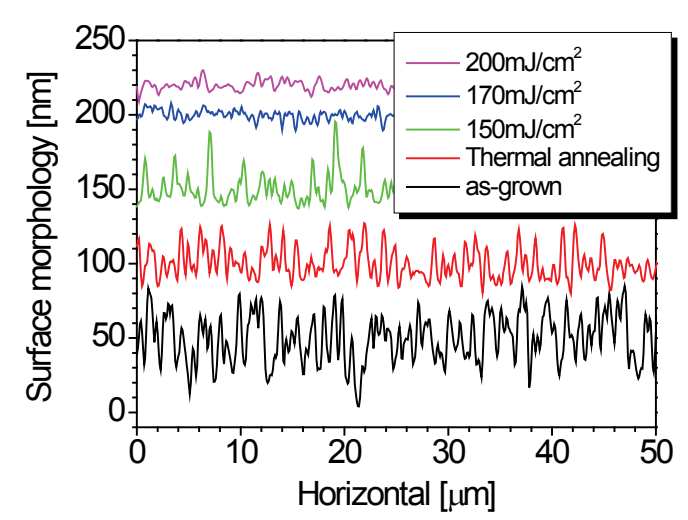

Fig. 2 Surface profile of the $\mathrm{ZnObuffer} \mathrm{layer.}$

Table 1 Surface roughness of the $\mathrm{ZnO}$ buffer layer.

\begin{tabular}{cccccc}
\hline & \multirow{2}{*}{$\begin{array}{c}\text { as- } \\
\text { grown }\end{array}$} & $\begin{array}{c}\text { Thermal } \\
\text { annealed }\end{array}$ & \multicolumn{3}{c}{ Laser-irradiated } \\
\cline { 3 - 6 } & & $\begin{array}{c}150 \\
\mathrm{~mJ} / \mathrm{cm}^{2}\end{array}$ & $\begin{array}{c}170 \\
\mathrm{~mJ} / \mathrm{cm}^{2}\end{array}$ & $\begin{array}{c}200 \\
\mathrm{~mJ} / \mathrm{cm}^{2}\end{array}$ \\
\hline RMS & $17.3 \mathrm{~nm}$ & $13.3 \mathrm{~nm}$ & $13.4 \mathrm{~nm}$ & $4.3 \mathrm{~nm}$ & $3.8 \mathrm{~nm}$ \\
\hline
\end{tabular}

irradiated surface with a laser fluence of $200 \mathrm{~mJ} / \mathrm{cm}^{2}$. The as-grown layer surface consists of small grains. The grain size was $200-300 \mathrm{~nm}$ and the surface roughness rms approximates $17.3 \mathrm{~nm}$. On the other hand, the laser-irradiated layer has a smooth surface. Fig. 2 and Table 1 show the surface profile and surface roughness rms of the buffer layers, respectively. The surface roughness of the buffer layer clearly decreased to $13.4-3.8 \mathrm{~nm}$ by laser irradiation around $150-200 \mathrm{~mJ} / \mathrm{cm}^{2}$. In most cases, a laser-irradiated surface will be more rough by surface texturization $[11,12]$. In our case, the roughness was improved with increasing the laser fluence in the low energy range, which is below the laser ablation threshold. It is considered that the $\mathrm{ZnO}$ grains are connected with each other by rapid laser annealing. A similar observation of the surface smoothing has been reported for a $\mathrm{KrF}$ excimer laser irradiation [13]. The roughness hardly changed by thermal annealing. For asgrown and the laser-irradiated buffer layers, only (002) and (004) peaks were obtained in the X-ray diffraction (XRD) measurement, which indicates that the layers are $c$-oriented.

\subsection{Growth of $\mathrm{ZnO}$ nano-crystals on laser-irradiated $\mathrm{ZnO}$ buffer layer}

Fig. 3(a) shows the SEM image of $\mathrm{ZnO}$ nanowires synthesized on the buffer layer. As mentioned in the experiment, the $\mathrm{ZnO}$ nanowires were grown at background argon gas of $27 \mathrm{kPa}$ for 12000 pulses. Almost nanowires are vertically well-aligned and grown on hexagonal cone-shape $\mathrm{ZnO}$ cores. In the $\mathrm{XRD},(002)$ and (004) peaks were detected from them (result not shown here), indicating the nanowires had high crystalline quality and preferential orientation along the c-axis. The lengths and diameters of the nanowires were $1 \mu \mathrm{m}$ and $100 \mathrm{~nm}$, respectively. More dense nanowires are grown when no buffer layer is introduced. Although the growth mechanism of $\mathrm{ZnO}$ nanowires on sapphire is still under investigation, the crystal polarity has a crucial role in both the nucleation and the growth of nanowires [14], because wurtzite $\mathrm{ZnO}$ has polar surfaces of
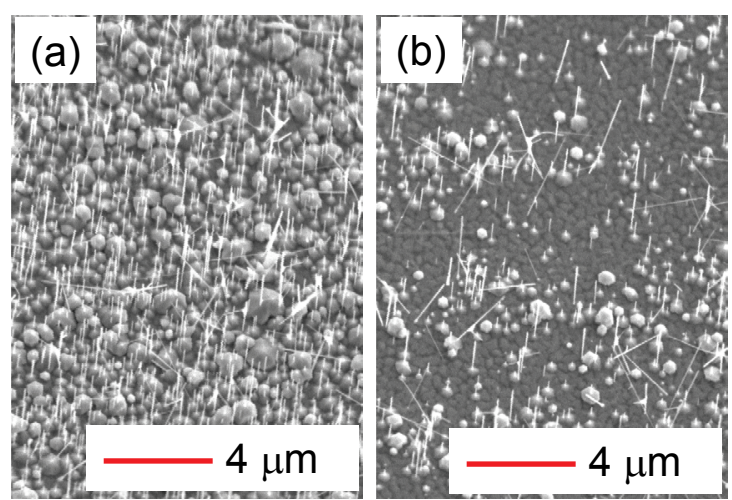

Fig. 3 SEM images of $\mathrm{ZnO}$ nanowires on (a) the buffer layer and (b) the laser-irradiated buffer layer.

positively charged $\mathrm{Zn}-(0001)$ and negatively charged O(0001). Y. Sun's group reported that an initial $\mathrm{ZnO}$ layer grown on sapphire under the $\mathrm{ZnO}$ nanostructure growth condition contains high-density threading dislocations (TD) [15], and Zn-polar nanorods (oriented in the $+c$ direction) grew on O-polar under-layer (oriented in the $-c$ direction) [16]. In our experiment, it is considered that the prepared $\mathrm{ZnO}$ buffer film consists of relatively low density TDs compared with the initial $\mathrm{ZnO}$ layer on sapphire, and prevent nanowire nucleation since the incoming $\mathrm{ZnO}$ incorporates much more effectively into the $\mathrm{ZnO}$ buffer layer. Similar result was reported by B. Q. Cao et al [17]. Fig. 3(b) shows the $\mathrm{ZnO}$ nanowires grown on the laser irradiated buffer layer. The fluence of the laser pulse was estimated to be $120 \mathrm{~mJ} / \mathrm{cm}^{2}$. The nanowire density clearly decreased due to laser irradiation to the buffer layer. Thus, the laser irradiation may decrease not only the surface roughness of the buffer layer, but also the TD density by connecting the grains each other. Although the growth mechanism of the nanowire on the laser-irradiated $\mathrm{ZnO}$ buffer layer by NAPLD have been under investigation, $\mathrm{ZnO}$ nanowire density can be controlled by laser irradiation. In addition, it is expected to control the growth position of the $\mathrm{ZnO}$ nanocrystals by selective irradiation, such as interfering laser irradiation. In this study, four-beam interference irradiation $[18,19]$ was utilized as shown in Fig.4.

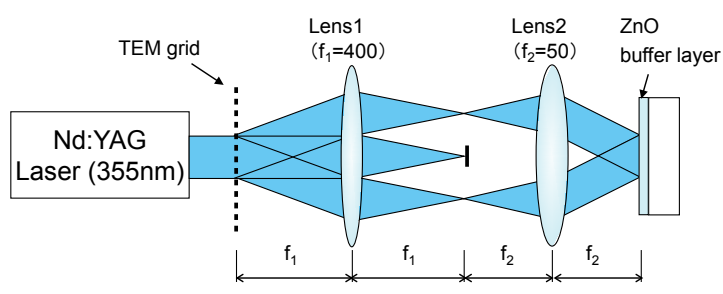

Fig. 4 Schematic of 4-beam laser interference irradiation.

\subsection{Introduction of laser interference irradiation}

A TEM grid (400 mesh) was used as a transmission beam splitter. A flat-top beam with a diameter of about 2 $\mathrm{mm}$ was irradiated to the beam splitter. The beam was split into several diffracted beams and collimated by the lens 1 . Only four beams were selected by a spatial filter and then illuminated on the same spot through the lens 2. By configuring a demagnification system, the spot diameter 


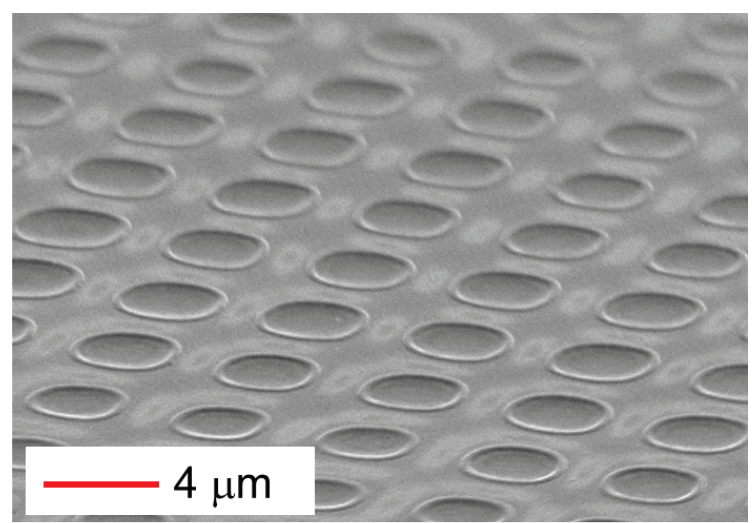

Fig. 5 SEM image of the buffer layer irradiated with the interfering laser beams.

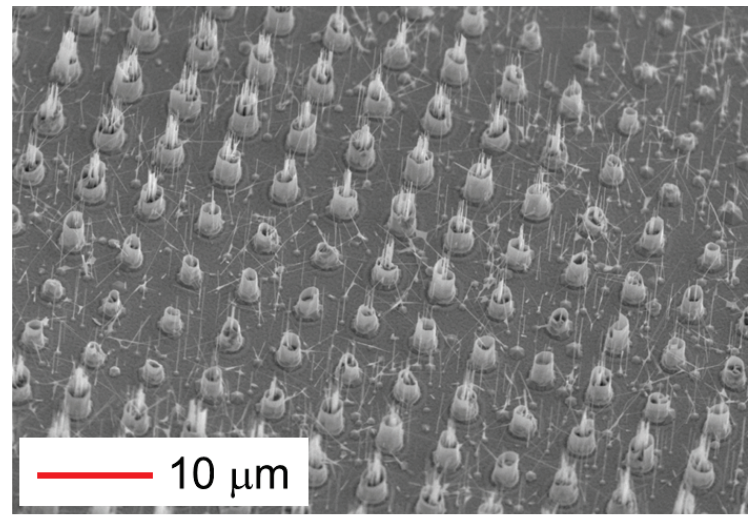

Fig. 6 SEM image of the $\mathrm{ZnO}$ nano-crystals grown on the buffer layer irradiated with the interfering laser beams.

was reduced to $\left(f_{2} / f_{1}\right) \cdot 2 \mathrm{~mm}$. An interference pattern is formed at the illuminated spot on the buffer layer. A pitch of the four-beam interference pattern can be calculated by $\left(f_{2} / f_{1}\right) \cdot d_{1} / \sqrt{ } 2$, where $d_{1}$ is the period of the transmission beam splitter. In the experiment, $d_{1}$ was $63.5 \mu \mathrm{m}$ (1 inch/400 mesh), and the focal lengths of lens 1 and lens 2 were $400 \mathrm{~mm}$ and $50 \mathrm{~mm}$, respectively. Thus, the pitch of the interference pattern was calculated to be $5.6 \mu \mathrm{m}$, and a spot size of each bright pattern was estimated to be $4.3 \mu \mathrm{m}$ at $1 / \mathrm{e}^{2}$ intensity. After a single shot interference irradiation, the periodic pattern was formed on the buffer layer, as shown in Fig.5. In this case, the buffer layer was ablated at a center of the irradiated spot, and ablation craters were formed due to the high laser fluence of about $1 \mathrm{~J} / \mathrm{cm}^{2}$. The pattern period of the periodic structure showed a good agreement with the numerical estimation. As the crater size depends on the laser fluence, the size of those craters was around $2.5 \mu \mathrm{m}$ in this case. After interference laser irradiation to the buffer layer, $\mathrm{ZnO}$ nano-crystals were subsequently grown on the layer. Fig. 6 shows the SEM images of the nano-crystals grown on the buffer layer irradiated with the interfering laser beams. Periodic structures are formed on the laser-irradiated buffer layer. $\mathrm{ZnO}$ nanowalls are synthesized from the edge of each irradiation spot. Only two characteristic peaks of (0002) and (0004) from the $\mathrm{ZnO}$ hexagonal wurtzite structure were observed from the structure in the XRD measurement. The $\mathrm{ZnO}$ nanowalls were preferentially grown along the circumferences of those craters. Since growth rate along the $+c$ direction is higher than along the $-c$ direction [14], surface polarity at the edge of the crater might be changed by laser ablation. Although we need to investigate the growth mechanism and a relation between the laser fluence and the structure of the $\mathrm{ZnO}$ nano-crystals, interference laser irradiation can be used as one of the effective technique to control the growth position and morphology of the $\mathrm{ZnO}$ nano-crystals synthesized by NAPLD.

\section{Conclusions}

We have demonstrated the periodic growth of the $\mathrm{ZnO}$ nano-crystals by introduction of a $\mathrm{ZnO}$ buffer layer and interference laser irradiation. $\mathrm{ZnO}$ nanowire density was decreased by laser irradiation to the $\mathrm{ZnO}$ buffer layer. We considered that the laser irradiation may decrease not only the surface roughness of the buffer layer, but also the TD density by connecting the grains each other. Four-beam laser interference was utilized to form the periodic pattern with a single laser shot. Interference laser irradiation to the buffer layer can be used as one of the effective technique to control the growth position and morphology of the $\mathrm{ZnO}$ nano-crystals synthesized by NAPLD.

\section{Acknowledgments and Appendixes}

A part of this study has been financially supported by Special Coordination Funds for Promoting Science and Technology from Japan Science and Technology Agency and Agency and Grant-in-Aid for Young Scientist (B) from the Japan Society for the Promotion of Science (No. 23760036).

\section{References}

[1] W. I. Park, G.C. Yi, "Electroluminescence in n-ZnO Nanorod Arrays Vertically Grown on p-GaN," Adv. Mater., 16, 87 (2004).

[2] R. Guo, J. Nishimura, M. Matsumoto, M. Higashihata, D. Nakamura, T. Okada, "Electroluminescence from $\mathrm{ZnO}$ nanowire-based $p$-GaN $/ n-\mathrm{ZnO}$ heterojunction light-emitting diodes," Appl. Phys. B 94, 33 (2009).

[3] M. H. Huang, S. Mao, H. Feick, H. Yan, Y. Wu, H. Kind, E. Weber, R. Russo, P. Yang, "RoomTemperature Ultraviolet Nanowire Nanolasers," Science, 292, 1897 (2001).

[4] J. Suehiro, N. Nakagawa, S. Hidaka, M. Ueda, K. Imasaka, M. Higashihata, T. Okada, M. Hara, "Dielectrophoretic fabrication and characterization of a $\mathrm{ZnO}$ nanowire-based UV photosensor," Nanotecnology, 17, 2567 (2006).

[5] R. Q. Guo, J. Nishimura, M. Ueda, M. Higashihata, D. Nakamura, T. Okada, "Vertically aligned growth of $\mathrm{ZnO}$ nanonails by nanoparticle-assisted pulsed-laser ablation deposition," Appl. Phys. A 89, 141 (2007).

[6] R. Guo, M. Matsumoto, T. Matsumoto, M. Higashihata, D. Nakamura, T. Okada, "Aligned growth of $\mathrm{ZnO}$ nanowires by NAPLD and their optical characterizations," Appl. Sur. Sci., 255, 9671 (2009).

[7] R. Guo, J. Nishimura, M. Matsumoto, M. Higashihata, D. Nakamura, T. Okada, "Density-Controlled Growth of ZnO Nanowires Via Nanoparticle-Assisted PulsedLaser Deposition and Their Optical Properties," Jpn. J. Appl. Phys., 47, 741 (2008). 
[8] D. S. Kim, R. Ji, H. J. Fan, F. Bertram, R. Scholz, A. Dadgar, K. Nielsch, A. Krost, J-R. Christen, U. Gosele, M. Zacharias, "Laser-Interference Lithography Tailored for Highly Symmetrically Arranged $\mathrm{ZnO}$ Nanowire Arrays," Small, 3, 76 (2007).

[9] S. Dai, Y. Wang, D. Zhang, X. Han, Q. Shi, S. Wang, Z. Du, "Fabrication of surface-patterned $\mathrm{ZnO}$ thin films using sol-gel methods and nanoimprint lithography", J. Sol-Gel Sci. Technol. 60, 17 (2011).

[10]H. J. Fan, B. Fuhrmann, R. Scholz, F. Syrowatka, A. Dadgar, A. Krost, M. Zacharias, "Well-ordered ZnO nanowire arrays on GaN substrate fabricated via nanosphere lithography", J. Crystal Growth, 287, 34 (2006).

[11]E. Cappelli, C. Scilletta, S. Orlando, V. Valentini, M. Servidori, "Laser annealing of amorphous carbon films", Appl. Sur. Sci. 255, 5620 (2009).

[12]B. K. Nayak, M. C. Gupta, "Femtosecond-laserinduced-crystallization and simultaneous formation of light trapping microstructures in thin a-Si:H films", Appl. Phys. A 89, 663 (2007).

[13] Y. Zhao, Y. Jiang, "Effect of KrF excimer laser irradiation on the properties of $\mathrm{ZnO}$ thin films", J. Appl. Phys., 103, 114903 (2008).
[14] G. P.-Merceroz, R. Thierry, P.-H. Jouneau, P. Ferret, G. Feuillet, "Compared growth mechanisms of Znpolar $\mathrm{ZnO}$ nanowires on O-polar $\mathrm{ZnO}$ and on sapphire", Nanotechnology, 23, 125702 (2012).

[15] Y. Sun, D. Cherns, R. P. Doherty, J. L. Warren, P. J. Heard, "Reduction of threading dislocations in $\mathrm{ZnO} /(0001)$ sapphire film heterostructure by epitaxial lateral overgrowth of nanorods", J. Appl. Phys., 104, 023533 (2008).

[16]D. Cherns, Y. Sun, "Defect reduction by epitaxial lateral overgrowth of nanorods in $\mathrm{ZnO} /(0001)$ sapphire films", Appl. Phys. Lett., 92, 051909 (2008).

[17] B. Q. Cao, J Zúñiga-Pérez, N. Boukos, C. Czekalla, H. Hilmer, J. Lenzner, A. Travlos, M. Lorenz, M. Grundmann, "Homogeneous core/shell $\mathrm{ZnO} / \mathrm{ZnMgO}$ quantum well heterostructures on vertical $\mathrm{ZnO}$ nanowires," Nanotechnology, 20, 305701 (2009).

[18] A.A.Maznev, T.F.Crimmins, K.A.Nelson, "How to make femtosecond pulses overlap," Opt. Lett., 23, 1378 (1998).

[19] Y. Nakata, N. Miyanaga, T. Okada, "Effect of pulse width and fluence of femtosecond laser on the size of nanobump array," Appl. Sur. Sci., 253, 6555 (2007).

(Received: June 8, 2012, Accepted: November 5, 2013) 